\title{
Extraction Of Natural (Dab Shell And Latkan) Dyes Blended It With Synthetic (Reactive Red And Methyel Orange) Dyes And Observe Their Dyeing Effects On Silk And Cotton Fibre.
}

\author{
${ }^{1}$ Mrs. Seatara khatun, ${ }^{2}$ Mrs. G.R.M. Astaq Mohal Khan, ${ }^{3}$ Md. Lutfor Rahman. \\ ${ }^{4}$ Md. Kobad Hossain, ${ }^{5}$ Debashis Talukdar and ${ }^{6}$ Mrs. Mahamuda Khatun.

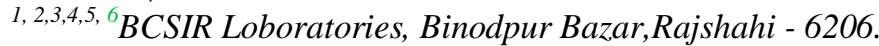

\begin{abstract}
Natural (Dab shell and Latkan) dyes were extracted by the conventional method. Blended it with synthetic (Reactive Red and Methyl orange) dyes, applied on silk and cotton fibre and observed their dyeing effects. It was found that in case of silk fibre using dab shell + latkan dyes + Reactive Red dye and dab shell + Latkan dye + Methyl orange produced deep chocolate and deep brown colour and shades. But in case of cotton fibre the colour and shade changed to light pink and light cream shade respectively. Light and washing fastness were also observed both kinds of fibre and found fine fastness to light and then washing.
\end{abstract}

Key Word: Dab-Shell, Latkan fruits, Reactive Red, Methyl Orange, Coper Sulphate, Acetic acid and Soap.

\section{Introduction}

Natural dyes are the best creation of Allah. They are obtained from the roots, barks leaves, fruits or wood of the plants. ${ }^{1}$ In ancient times all dyes were obtained from natural sources. ${ }^{2}$ Natural dyes exhibit better biodegradability, compatibility with environment and possess lower toxicity and non allergic reaction on human body ${ }^{3,4}$. Some natural dyes give long life shade one cotton fibre ${ }^{5}$. A dye is a substance that observes strongly in the visible region or physical attraction between the dyes and the dyed substance ${ }^{6}$. For a substance acts as a dye which must be able to fix itself to the fibre and must be resistance to acid, alkali and water ${ }^{7}$.

(Indigo) a blue dye, ( catechu) a brown dye, ( Turmeric) a yellow dye, ( Eucalyptus) a brown dye all are obtained from the different parts of the plants. They chemically identical to natural dyes ${ }^{8}$. Similarly Dab shell (Cocos nucifera) a chocolate dye obtained from its waste shell and latkan (Bixa orellana) orange dye obtained from its seed coat. At present, the textile industry is a flourishing in Bangladesh. The dyeing section of this industry is fully dependent on improved synthetic dyes. But many of them have got allergic reaction or human body ${ }^{9}$. Considering it in mind our present work has been under taken with a view to reduce the direct use of synthetic dye as well as to increase the use of natural dyes either alone or blended with synthetic dyes and applied on silk and cotton fibre and observe their dyeing effects.

\section{Materials and methods}

(a) Extraction of dab shell dye :

Waste green dab shell were collected from bazar and cut into flakes manually. The flakes were then smashed in a wooden mortar. The smashed flakes were then boiled with water in the ratio 1:50 for 8 hours in a stainless steel beaker. The extraction was repeated $2^{\text {nd }}$ and $3^{\text {rd }}$ times with water in the same condition. The extracts were filtered through a fine cloth to remove adhering materials. The filtrate was then concentrated by heating to requistic density. This concentrated pest like mass was used as dye.

\section{(b) Extraction of latkan dye :}

Warm water method :

$50 \mathrm{gm}$ of ripe mature latkan seeds were taken in ground joint conical flask and 100 one of warm water was poured in to it. Then the flask was put on a mechanical shaker and shaked one our at a temperature of $80^{\circ} \mathrm{c}$. After then it was allowed to stand for one our and the soluble portion was decanted from the seeds carefully. Finally the soluble portion was dried and obtained the dye (past like mass).

(c)Degumming of silk and cotton fibre:

For degumming soap solution of strength $3.5 \mathrm{~g} / \mathrm{litre}$ was prepared by adjusting the ph 10.5 . Now the silk and cotton fibre were dipped into the soap solution and then heated at $100^{\circ} \mathrm{c}$ for one hour. After degumming both the fibre were washed 2-3 times with distilled water. 


\section{Dyeing of silk and cotton fibres :}

Dyeing is the process by which the dye in applied to substance being dyed ${ }^{10}$. Now the mordanting bath was prepared with $0.5 \%$ copper sulphate in a $250 \mathrm{ml}$ beaker in a ratio (1:20). I am degumming silk fibre was dipped into the mordanting bath and heated to boiling for 30 minutes with string. Here mordant was acted as a key or bridge between the dye and fibre ${ }^{11}$. Then the mordanted silk fibre was taken out squeeze and dried at room temperature. Two dye bath were prepared by dissolving $1 \mathrm{gm}$ Dab shell dye, $1 \mathrm{gm}$ Latkan dye and $0.20 \mathrm{gm}$ Reactive Red dye and $1 \mathrm{gm}$ Dab shell dye, $1 \mathrm{gm}$ latkan dye and 0.20 Methyl orange separately. Now the bath was heated for 30 minutes with occational stirring. The bath were allowed to cool down and filtered. The mordanted silk fibre sample was dipped into the filtrate solution and again heated for 30 minutes at $90^{\circ} \mathrm{c}$ and the dyeing was continued for another one hour. The dyes fibre were then taken out squeezed and treated with $0.1 \%$ sodium dichromate solution in a separate bath and heated at $90 \mathrm{c}$ for 20 minutes. The dyed fibres were then taken out the bath, washed with soap rinsed well with $1 \%$ acetic acid solution and dried at room temperature. Shades were obtained which shown in table - 1 . The same dyeing procedure was followed in case of cotton fibre.

\section{Fastness test:}

Light and washing fastness were measured with the help of Grey Scale fastness grade- 5 followed by I.S.O Recommendation.

\section{(a) Light fastness :}

The dyed sample of silk and cotton fibres were exposed to sunlight in air for 150 hours and changed in colour was measured with the help of Grey Scale. The results were shown in table-2.

\section{(b) Washing Fastness:}

All the dyes sample of silk and cotton fibres were washed with 3.5\% soap solution separately for 3-4 times squeezed and allowed to dry in sunlight. The washing fastnesses were measured with the help of GreyScale which was shown table-2.

\section{Results and Discussion}

From the result shown in table 1, it is observed that when the silk and cotton fibres were dyed with dab shell dye \& latkan dye blended with Reactive Red dye and Methyl orange dye, they produced deep shades on silk fibres and light shades on cotton fibre with same concentration, dyeing temperature and dying time.

From the result in table2, it is fount that blended dyed exhibited somewhat poor light and washing fastness on cotton fibres than that on silk fibres on exposed to sunlight at 150 hours due to the binding capacity. The reactive and Methyl orange were used in silk dyeing to give wide range of shads which have very good fastness to light and washing ${ }^{13}$. Therefore it can be concluded that the blended dyed Reactive Red dye and Methyl orange are best utilized for dyeing of silk fibre but not for cotton fibre. Because the bending capacity of silk fibre is more superior than the cotton fibre.

Table-1 :- Dyeing effects of silk and cotton fibre with natural ( Dabshell dye +Latkan) dye blended with Reactive Red and Methyl orange.

\begin{tabular}{|c|c|c|c|}
\hline Types of fibre & Mordanting used & Dyeing & Nature of shades \\
\hline Silk fibre & $\begin{array}{l}\text { 0.5\% copper sulphate and } \\
1 \% \mathrm{Na}_{2} \mathrm{Cr}_{2} \mathrm{O}_{7}\end{array}$ & $\begin{array}{l}1 \text { gm Dab shell dye }+1 \\
\text { gm Latkan dye }+0.02 \% \\
\text { Reactive Red. }\end{array}$ & Deep chocolate \\
\hline Silk fibbre & “ & $\begin{array}{l}1 \text { gm Dab shell dye }+1 \\
\text { gm Latkan dye }+0.02 \% \\
\text { Methyl orange. }\end{array}$ & Deep brown \\
\hline Cotton fibre & “" & $\begin{array}{l}1 \text { gm Dab shell dye }+1 \\
\text { gm Latkan dye }+0.02 \% \\
\text { Reactive Red. }\end{array}$ & Light pink \\
\hline Cotton fibre & “" & $\begin{array}{l}1 \text { gm Dab shell dye }+1 \\
\text { gm Latkan dye }+0.02 \% \\
\text { Methyl orange. }\end{array}$ & Light cream \\
\hline
\end{tabular}


Table-2 :- Light and washing fastness of natural dye blended with Reactive Red and Methyl orange on silk and

\begin{tabular}{|c|l|c|c|}
\hline \multicolumn{5}{|c|}{ cotton fibre. } \\
\hline Types of fibre & \multicolumn{1}{|c|}{ Dyeing } & Light fibres & Washing fastness \\
\hline Silk fibre & $\begin{array}{l}\text { Dabshell dye + Latkan dye + } \\
\text { Reactive Red }\end{array}$ & 5.2 & 5.0 \\
\hline Silk fibre & $\begin{array}{l}\text { Dabshell dye + Latkan dye + } \\
\text { Methyl orange. }\end{array}$ & 4.5 & 5.0 \\
\hline Cotton fibre & $\begin{array}{l}\text { Dabshell dye + Latkan dye + } \\
\text { Reactive Red. }\end{array}$ & 3.5 & 3.2 \\
\hline Cotton fibre & $\begin{array}{l}\text { Dabshell dye + Latkan dye + } \\
\text { Methyl orange. }\end{array}$ & 3.5 & 3.5 \\
\hline
\end{tabular}

\section{Conclusion}

The dyeing effect, light and washing fastness of natural dyes on between the two fibres silk and cotton fibre blended with synthetic dyes it was found that the silk fibre has got good dyeing effect than that of cotton fibre, similarly light and washing fastness has also fine fastness on silk fibre due to its superior binding capacity than the cotton fibre. So it may be concluded that the silk fibre is best utilized for dyeing for its higher binding capacity.

\section{References}

[1] A.F.HILL, Economic Botany, $2^{\text {nd }}$ edition, 1951,225.

[2] E.R, Trotman, Dyeing and chemical Technology and Textile Fibres, $5^{\text {th }}$ edition $1975,2,618$

[3] M.M. Alam, M.L. Rahman and M.Z. Haque, Bangladesh J.Sci.Ind.Res.2007,217-222.

[4] V Kumar and B.V. Bharti, The Indian Textile journal, 1998,18-20.

[5] F.A. Marganet and A.F. Furry, Rayon Textile, 1945,26,603.

[6] L.O. Smith and S.T. Gristol, Organic chemistry p-652.

[7] I.L. Finar, Organic chemistry, $3^{\text {rd }}$ edition, 1959,1,741.

[8] R.T. Adroska, Natural dyes and Henna dyeing, 1971.

[9] A.S. Tulson, Textile dye, 1999, p-22.

[10] (10)C.R. Noller, Chemistry of organic compounds, p-74.

[11] (11)S.R. Cockelt and K.H. Hilton, Dyeing of cellulose fibre, 1961, p-135.

[12] (12)C.C. Wilcock and Ashworth, Dyeing with Coal tar dyestuff, 1964, $6^{\text {th }}$ edition, p-66. 